\title{
Langerhans Cell Histiocytosis Involving the Thyroid and Parathyroid Glands
}

\author{
Wai Ming Yap, MRCPath, Khoon Leong Chuah, FRCPA, Puay Hoon Tan, FRCPA \\ Department of Pathology, Singapore General Hospital, Outram Road, Singapore
}

\begin{abstract}
Langerhans cell histiocytosis (LCH) is a rare illness, and the disease afflicting the thyroid gland is very uncommon, even in the presence of multisystem involvement. In this report, we document histologically, for the first time, concurrent involvement of the thyroid and parathyroid glands by LCH. A young Chinese woman with a history of diabetes insipidus and hypogonadism underwent a total thyroidectomy for enlarged thyroid gland secondary to $\mathrm{LCH}$ causing airway obstruction. Microscopic examination of the excised specimen disclosed CD1a- and S-100-positive LCH cells involving the thyroid and parathyroid glands. In a patient with LCH affecting the thyroid gland, parathyroid gland disease should be suspected when the serum calcium levels are depressed in association with an inappropriate serum parathyroid hormone level, such as a normal parathyroid hormone level in this case.
\end{abstract}

KEY WORDS: CD1a, Langerhans cell histiocytosis, Thyroid, Parathyroid, S-100.

Mod Pathol 2001;14(2):111-115

Since the first description of Langerhans cell histiocytosis (LCH) more than a century ago (1), this poorly understood entity has been subjected to a plethora of confusing terms that beg clearer definition (2). Currently, the preferred term is Langerhans cell histiocytosis $(3,4)$ replacing the term histiocytosis $X$ because the Langerhans cell is believed to play a central role in the pathogenesis of this heterogeneous group of disease whose clinical manifestation ranges from benign, solitary bone lesion to fatal, multisystemic, life-threatening lymphoproliferative disorders (Litterer-Siwe syndrome) (2). The classic triad of exopthalmos, diabetes insipidus, and bone destruction or Hand-Schuller-Christian disease is placed between the two ends of the spectrum of disease. However,

Copyright (C) 2001 by The United States and Canadian Academy of Pathology, Inc.

VOL. 14, NO. 2, P. 111, 2001 Printed in the U.S.A.

Date of acceptance: September 25, 2000.

Address reprint requests to: Dr. Khoon Leong Chuah, Department of Pathology, Singapore General Hospital, Outram Road, Singapore 169608,

Singapore; e-mail: gptckl@sgh.com.sg; fax: 65-227-6562. there is a current tendency to discourage the usage of old terms such as Litterer-Siwe syndrome and HandSchuller-Christian disease and to categorize Langerhans cell histiocytosis as restricted or extensive disease to highlight the common identity of the underlying pathologic process (5).

$\mathrm{LCH}$ is an uncommon disease with an annual incidence of 4 to 5.4 per million (3). Involvement of the thyroid by LCH is very rare, even in extensive disease $(6,7)$. In this case report, we describe simultaneous involvement of the thyroid and parathyroid glands by LCH in a young Chinese woman with diabetes insipidus and hypogonadism. To the best of our knowledge, this is the first histological documentation of $\mathrm{LCH}$ afflicting the parathyroid gland in the literature.

\section{Case History}

A 19-year-old Chinese woman with a 3-year history of what was believed to be idiopathic pituitary diabetes insipidus and idiopathic hypogonadotrophic hypogonadism, as suggested on relevant blood investigations, water deprivation test, and computedtomography (CT) scan of the head, presented in December 1993 for stridor due to a goiter-causing airway obstruction. She was found to be hypothyroid with a raised serum thyroid-stimulating hormone (TSH) level on blood investigations. Antithyroglobulin and antimicrosomal antibodies were not detected in the serum. Although she was scheduled for a total thyroidectomy, the operation was canceled because of hypothyroidism. She was given thyroxine replacement therapy and a course of dexamethasone orally. The stridor resolved with dexamethasone, and the steroid therapy was gradually stopped in March 1994. However, in April 1994, she was seen at the Accident and Emergency department for stridor of 2 days' duration, after which she became cyanotic and collapsed, requiring intubation and artificial respirator support initially. On examination, she was afebrile and found to be tachycardic (pulse rate was $110 / \mathrm{min}$ ), with a blood pressure reading of 120/80 mm Hg. She was alert and responsive. No edema or jaundice was noted. Skin rash and exophthalmos were absent. She was not thought to be of short stature. Clinically, the 
thyroid gland was believed to be diffusely enlarged. Significantly, she had poorly developed breasts in addition to absent pubic and axillary hair. No obvious abnormality was detected when the lungs and abdomen was examined. Examination of the central nervous and musculoskeletal systems was normal, without any evidence of disturbed vision and bone or joint tenderness and swelling. Chest X-ray revealed haziness of both lung fields without any abnormality seen in the skeleton and ribs. CT scan of the neck and lung disclosed diffusely enlarged thyroid resulting in compression of the tracheal air column as well as diffuse consolidation of both lungs. The clinical impression was that of multinodular goiter causing airway obstruction with associated pneumonia.

Blood investigation revealed the presence of leukocytosis with predominance of neutrophils. The hemoglobin level and platelet count were normal. Serum electrolytes, creatinine, albumin, total bilirubin, protein, and osmolality levels were normal except for a depressed level of total serum calcium of $1.96 \mathrm{mmol} / \mathrm{L}$ (normal range: $2.10-2.60 \mathrm{mmol} / \mathrm{L}$ ). The serum alanine transaminase and aspartate transaminase levels were slightly elevated. Thyroid function test revealed hypothyroidism with free serum $\mathrm{T}_{4}$ level being $7.7 \mathrm{pmol} / \mathrm{L}$ (normal range: 10.3-31 pmol/L) without compensatory increase in TSH level, the TSH level being $2.1 \mathrm{mU} / \mathrm{L}$ (normal range: $0.5-5 \mathrm{mU} / \mathrm{L}$ ). There was also an absence of compensatory increase in intact serum parathyroid hormone (PTH) level, the level being $8.2 \mathrm{pmol} / \mathrm{L}$ (normal range: 4.7-48.5 pmol/L). Folliclestimulating hormone, luteinizing hormone, and prolactin levels continued to be low. No serum growth hormone level assessment was performed.

The patient was treated initially with intravenous antibiotics and a short course of steroids. The following day, an emergency total thyroidectomy was performed with the operative findings of a diffusely enlarged thyroid gland adherent to the strap muscles, trachea, and esophagus and extending retropharyngeally. The thyroid was of firm consistency. Clinically, three parathyroid glands were thought to be removed with the thyroid gland and the left inferior parathyroid gland was believed to be implanted into the right sternomastoid muscle. Postoperatively, her recovery was complicated by hypocalcemia associated with depressed serum PTH levels, and this necessitated calcium supplements. A repeat chest $\mathrm{x}$-ray revealed no obvious abnormality. She was advised to undergo a bone scan, an ultrasound of the hepatobiliary system, and a bone marrow biopsy, which she declined, citing financial constraints. However she allowed blood investigations for serum cortisol and adrenocorticotrophin hormone (ACTH) levels and was found to have hypocortisolism with elevated ACTH levels. No serum aldosterone level was performed. CT scan of the head performed in May 1994 revealed an enhancing area in the region of the hypothalamus that was subsequently further delineated on brain magnetic resonance imaging, the latter disclosing a mass measuring $2 \times 1 \times 1 \mathrm{~cm}$, extending from the hypothalamus to the suprasellar cistern, compatible with LCH deposit. Her postoperative problems related to multifocal LCH disease included diabetes insipidus, hypogonadism, hypothyroidism, and hypoparathyroidism. When her condition was stabilized, she was discharged. Subsequently, she was given six courses of chemotherapy (vincristine) and dexamethasone. She refused any further radiological investigations, and her follow-up in the clinic was irregular, although she was apparently well, except for persistent hypocalcemia on follow-up blood tests. She was alive 6 years postoperatively, as evidenced by a recent visit to another hospital for which clinical notes were not available for review.

\section{MATERIALS AND METHODS}

The excised total-thyroidectomy specimen was received in formalin. It was extensively sampled and processed for routine hematoxylin and eosinstained sections. No fresh tissue was available for electron microscopy studies.

Five- $\mu \mathrm{m}$ sections from formalin-fixed, paraffinembedded tissues were stained with antibodies against pan-cytokeratin marker (AE 1/3, DAKO), CD1a (Immunotech 1590, Newcastle, United Kingdom), CD4 (Novocastra, France), CD68 (KP1, DAKO, Denmark) and S-100 (DAKO) using the avidin-biotin complex method with the microwave antigen retrieval technique, except for S-100, for which no retrieval technique was used. Appropriate positive and negative controls were used throughout. The positive controls used were skin, thymus, tonsil, tonsil, and schwannoma for $\mathrm{AE} 1 / 3$, CDla, CD4, CD68, and S-100 respectively.

\section{PATHOLOGIC FINDINGS}

\section{Macroscopic Findings}

The excised total-thyroidectomy specimen received measured $8 \times 5 \times 2 \mathrm{~cm}$ and weighed $50 \mathrm{~g}$. The specimen appeared incomplete posteriorly. On cut section, the tissue appeared whitish with yellowish areas and interspersed areas of hemorrhage. No definite tumor nodules were noted.

\section{Microscopic Findings}

The thyroid tissue was diffusely infiltrated by sheets and islands of histiocyte-like cells containing vesicular nuclei with an indented, notched, grooved or "coffee bean"-shaped appearance, one or two nucleoli, and abundant lightly eosinophilic to eosinophilic cy- 
toplasm. Some binucleated and occasional multinucleated cells were seen. Eosinophils were present in variable numbers, and there were accompanying lymphocytes that formed fairly dense aggregates in several areas. No Charcot-Leyden crystals were noted. Although residual thyroid follicles were noted within the tumor, a significant number of thyroid follicles were colonized by the histiocyte-like cells that formed aggregates within the follicular lumina (Fig. 1). Necrosis was absent, and there were areas of hemorrhage. There was extrathyroid extension of the lesional cells into the surrounding skeletal and adipose tissue, including the parathyroid glands, composed of chief and clear cells (Fig. 2).

Lymphocytic thyroiditis without oncocytic change of the thyroid epithelium was noted throughout the rest of the thyroid tissue. However, there was no evidence of a coexisting papillary carcinoma or any other nodular proliferation within the rest of the thyroid gland. The parathyroid tissue unaffected by LCH was unremarkable.

\section{Immunohistochemistry}

The lesional cells stained positively for CDla (Fig. 3) and S-100 (Fig. 4). A patchy positive staining was seen with CD68. The stains for CD4 and cytokeratin were negative.

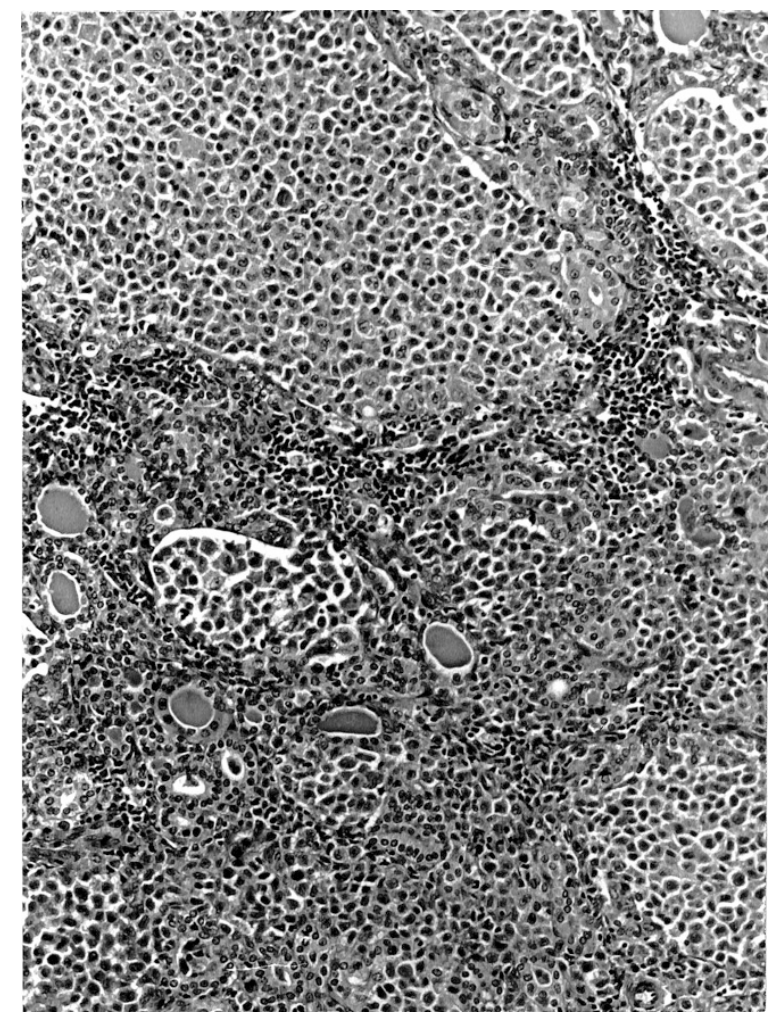

FIGURE 1. Langerhans cell histiocytosis cells diffusely infiltrating the thyroid gland. Note the residual thyroid follicles as well as thyroid follicles colonized by Langerhans cell histiocytosis cells (H\&E, original magnification, $\times 100$ ).

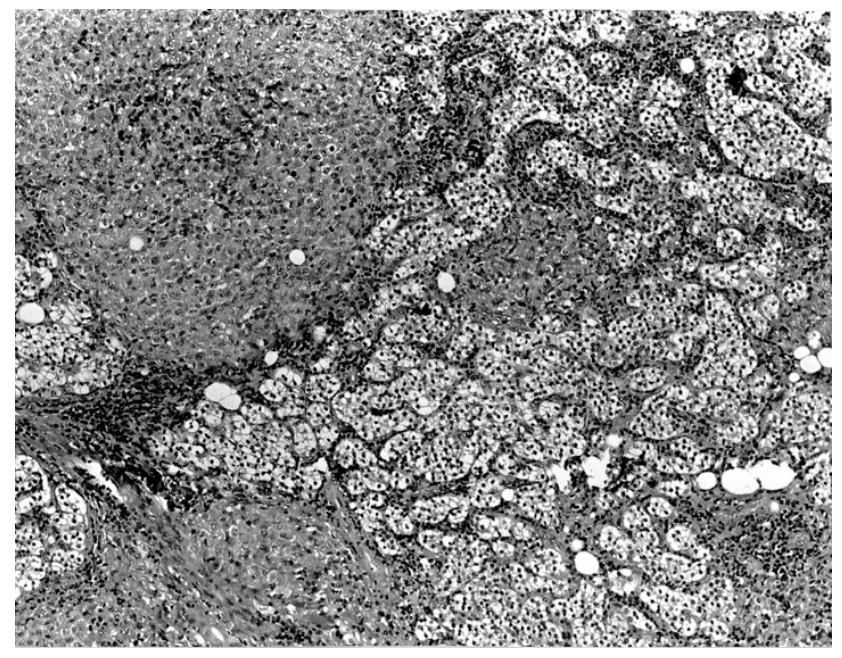

FIGURE 2. Langerhans cell histiocytosis cells spilling into the adjacent parathyroid gland, composed of clear cells (H\&E, original magnification, $\times 100$ ).

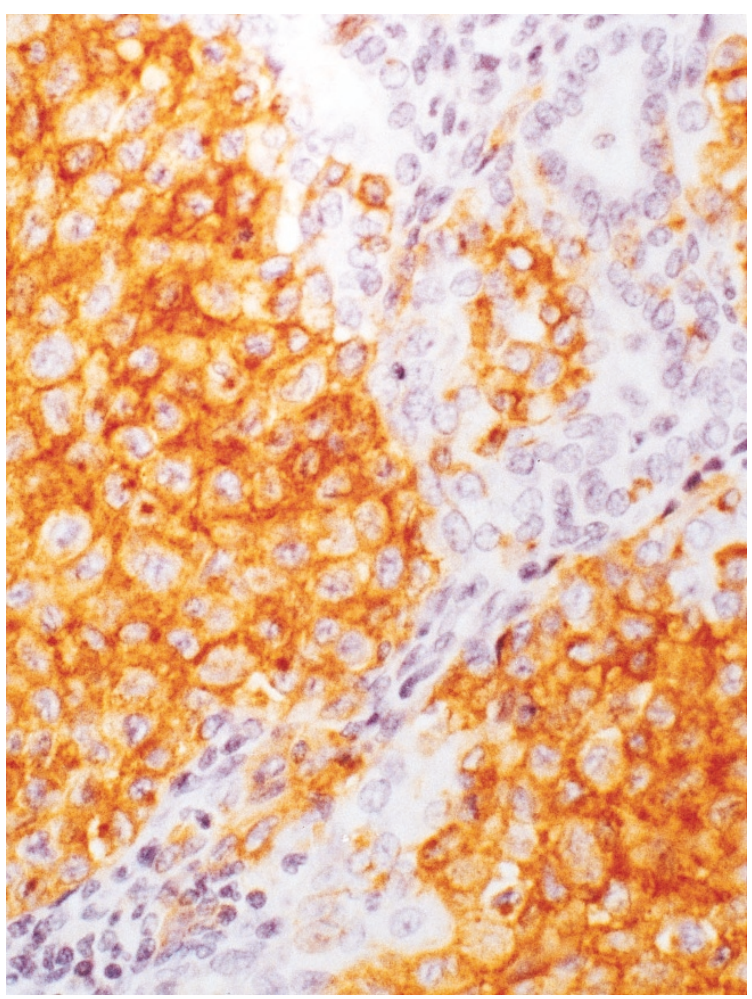

FIGURE 3. Antibodies against CDla highlighting islands of Langerhans cell histiocytosis cells with intervening residual thyroid follicle (Avidin biotin complex method; original magnification, $\times 200$ ).

The combined light-microscopic and immunohistochemistry findings were definitive for a diagnosis of LCH involving both the thyroid and parathyroid glands.

\section{DISCUSSION}

Thyroid involvement by LCH is rare (6-8), with the age range of the afflicted patients being from 2 


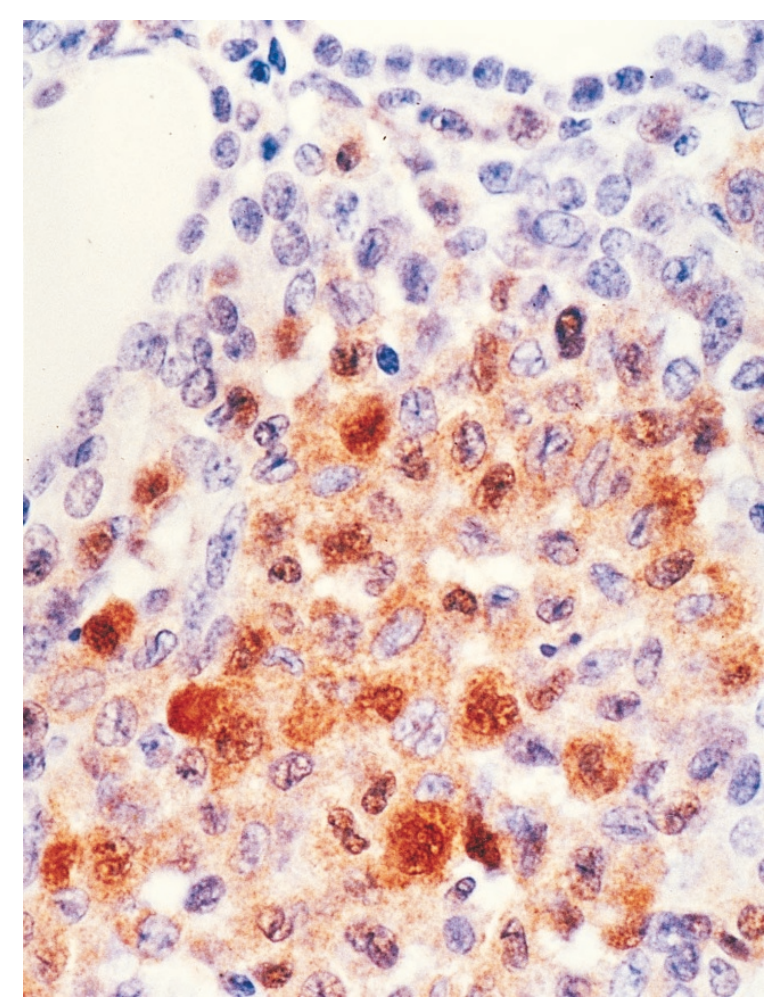

FIGURE 4. Langerhans cell histiocytosis cells with grooved nuclei decorated by antibodies against S-100 (Avidin-biotin complex method; original magnification, $\times 400)$.

54 months to 55 years and not associated with sexual predilection (8). $\mathrm{LCH}$ isolated to the thyroid alone is believed to be even rarer $(7,9)$, although in the series by Thompson et al. (8), isolated thyroid involvement is slightly more common than is thyroid involvement forming part of multifocal disease. Thyroidal disease secondary to $\mathrm{LCH}$ may present as thyroid enlargement because of infiltration of the thyroid by LCH (10). However, there are instances in which the foci of LCH may not be appreciated grossly, the microscopic foci of $\mathrm{LCH}$ being found incidentally only on histologic examination, and in such instances, the thyroid enlargement may be due to other coexisting pathologic process such as adenomatoid goiter, lymphocytic thyroiditis, or papillary carcinoma (10). Occasionally, the manifestation of thyroid disease may precede subsequent multisystem involvement in $\mathrm{LCH}$ (11). Pituitary disease secondary to LCH (5) is a known complication, with the prevalence of diabetes insipidus ranging from $5 \%-50 \%$ in various series; however, overt functional impairment of anterior pituitary is less common, with the incidence ranging from $2.4 \%$ to $5.8 \%$. Simultaneous involvement of the pituitary and thyroid glands had been described (12), as in our case. However, it is unclear why the pituitary lesion was not detected earlier by CT scan in our case because it is likely that the patient had fairly extensive sellar disease given the fact that there was anterior and posterior pituitary gland dysfunction. Interestingly, in our case, besides the presence of multifocal illness, the parathyroid gland was affected by the disease process, a phenomenon that could be deduced by the lack of a compensatory increase in serum-intact PTH level in the face of hypocalcemia. The presence of primary hypocortisolism in our patient was not clear, and the possibility of LCH affecting the adrenal has to be considered, although this could not be proven without further investigation.

The histological features of LCH have been well documented, and the features are akin to those described in our patient (5). In the thyroid, the proliferation of LCH cells often extends beyond the confines of the capsule, causing adherence of the thyroid gland to the surrounding soft tissue or muscle as in our patient (10). It is therefore not surprising that the parathyroid glands are affected in our case because the parathyroid glands are intimately related to the thyroid gland in terms of anatomical site, and they are most likely afflicted by the disease when the LCH cells infiltrate beyond the thyroid capsule.

On immunohistochemistry (5), the LCH cells typically display a similar profile to both resting and activated Langerhans cells. Strong and diffuse positive stain for CD1a and S-100 positivity are characteristic features as in our case. Because aberrant expression of macrophage marker CD68 occurs only in a substantial minority of cases of LCH, it is not surprising that only patchy positivity is noted in our case. In fact, CD68 antigen expression has been reported as absent or minimally expressed in normal Langerhans cells (13). It is, however, unclear why the lesional cells in our case failed to stain with CD4 as one would expect $(5,6)$. On an ultrastructural level (5), Birbeck or Langerhans granules, which represent invaginations of plasma membrane and laid the foundation that led to the suggestion that Langerhans cells are the progenitor of the LCH cells (14), are typically identified in LCH cells. Under the recommendation of the Writing Group of the Histiocyte Society (4), a definitive diagnosis of LCH can only be rendered when either there is demonstration of Birbeck granules on electron-microscopic study or there is the demonstration of CDla expression with appropriate histological settings, the latter being present in our case.

In the thyroid, LCH had been mistaken for poorly differentiated carcinoma on histology (15) and papillary carcinoma on fine-needle aspiration (6). However, a diagnosis of LCH can be established if attention is paid to the fact that the lesional cells possess more abundant granular cytoplasm with low nuclear-cytoplasmic ratio and prominent nuclear folding; and the concomitant presence of eosinophils favors a diagnosis of LCH. In difficult 
cases, the usage of appropriate immunohistochemical stains will settle the issue because LCH cells do not stain for cytokeratin and thyroglobulin antibodies but are S-100 and CD1a positive (5). However, the possibility of LCH coexisting with papillary carcinoma has to be entertained, and in such instances, careful observation of the morphologic features with the aid of immunohistochemical stains will allow accurate identification of the various pathological processes present $(16,17)$. A diagnosis of leukemia or myeloproliferative disorder involving the thyroid can be excluded in the presence of normal peripheral blood morphology in the appropriate clinical settings $(6,17)$.

The etiology and pathogenesis of LCH are still unclear, and there is no conclusive correlation between prognosis and histologic features in LCH (5). Clinical features are more important parameters to gauge the disease outcome. Multiple organ system involvement appears to correlate positively with recurrence but not necessarily with disease progression in the absence of significant hemopoietic, pulmonary, or hepatic dysfunction (5). Our patient would best be classified as having extensive LCH disease with visceral organ involvement and diabetes insipidus, not associated with signs of hepatic, pulmonary, or hemopoietic system dysfunction as defined by Lahey's criteria (Table 1) (18). Because the presence of pulmonary, hepatic, or hemopoietic dysfunction signifies significant systemic disease, with death usually occurring within a year (8, 10 ), it is not surprising that our patient is still alive 6 years after the first manifestation of her thyroid disease secondary to $\mathrm{LCH}$.

In summary, a rare case of simultaneous involvement of the thyroid, parathyroid, and pituitary

TABLE 1. Lahey's Criteria for Organ Dysfunction (18)

\begin{tabular}{lc}
\hline Hepatic & $<5.5 \mathrm{~g} / \mathrm{dL}$ \\
Total protein & $<2.5 \mathrm{~g} / \mathrm{dL}$ \\
Albumin & $>1.5 \mathrm{mg} / \mathrm{dL}$ \\
Total bilirubin & \\
Edema & \\
Ascites & \\
Pulmonary & \\
Tachypnea & \\
Dyspnea & \\
Cyanosis & \\
Cough & \\
Pneumothorax & $<10 \mathrm{~g} / \mathrm{dL}^{3}$ \\
Pleural Effusion & $<4000 / \mathrm{mm}^{3}$ \\
Hematopoietic & $<1500 / \mathrm{mm}^{3}$ \\
Hemoglobin & $<100000 / \mathrm{mm}^{3}$ \\
Leukocyte count & \\
Neutrophils & \\
Platelets &
\end{tabular}

glands by LCH is presented. The possibility of parathyroid gland disease in a patient with LCH afflicting the thyroid gland has to be entertained if the pathological process in the thyroid is extensive. In such an instance, an abnormal serum calcium level in conjunction with an inappropriate serum PTH level may provide the initial clues of parathyroid gland involvement.

\section{REFERENCES}

1. Hand A. General tuberculosis. Trans Pathol Soc Philadelphia 1883;16:282.

2. Vigorita VJ. Orthopaedic pathology. Philadelphia: Lippincott Williams \& Wilkins; 1999. p. 464-8.

3. Nicholson HS, Egeler RM, Nesbit ME. The epidemiology of Langerhans cell histiocytosis. Hematol Oncol Clin North Am 1998;12(2):379-85.

4. The Writing Group of the Histiocyte Society. Histiocytosis syndromes in children. Lancet, 1987;I:208-9.

5. Herzog KM, Tubbs RR. Langerhans cell histiocytosis. Adv Anat Pathol 1998;5(6):347-58.

6. Kitahama S, Iitaka M, Shimizu T, Serizawa N, Fukasawa N, Miura S, et al. Thyroid involvement by malignant histiocytosis of Langerhans cell type. Clin Endocrinol 1996;45:35763.

7. Sahoo M, Karak AK, Bhatnagar D, Bal CS. Fine needle aspiration cytology in a case of isolated involvement of thyroid with Langerhans cell histiocytosis. Diagn Cytopathol 1998; 19:33-7.

8. Thompson LD, Wenig BM, Adair CF, Smith BC, Heffess CS. Langerhans cell histiocytosis of the thyroid: a series of 7 cases and a review of the literature. Mod Pathol 1996;9: 145-9.

9. Thompson LDR. Langerhans cell histiocytosis isolated to the thyroid gland. Eur Arch Otorhinolaryngol 1996;253:62-5.

10. Wenig BM, Heffess CS, Adair CF. Atlas of endocrine pathology. Philadelphia: WB Saunders; 1997. pp. 136-7.

11. Ho KH, Chong AP, Thai AC. Langerhans cell histiocytosis presenting as a goiter: a case report. Ann Acad Med Singapore 1993;22(4):598-602.

12. Kirchgraber PR, Weaver MG, Arafah BM, Abdul-Karim FW. Fine needle aspiration cytology of Langerhans cell histiocytosis involving the thyroid gland. A case report. Acta Cytol 1994;38:101-6.

13. Malone M. The histiocytosis of childhood. Histopathology 1991;19:105-19.

14. Nezelof C, Basset F, Rousseau MF. Histiocytosis X: histiogenetic arguments for a Langerhans cell origin. Biomedicine 1973;18:365-7.

15. Coode PE, Shaikh MU. Histiocytosis X of the thyroid masquerading as thyroid carcinoma. Hum Pathol 1988;19:23941.

16. Goldstein PE, Layfield LJ. Thyromegaly secondary to simultaneous papillary carcinoma and histiocytosis X. Acta Cytol 1991;35(4):422-6.

17. Saiz E, Bakotic BN. Isolated Langerhans cell histiocytosis of the thyroid: a report of two cases with nuclear imagingpathologic correlation. Ann Diagn Pathol 2000;4(1):23-8.

18. Lahey ME. Histiocytosis $X$-an analysis of prognostic factors. J Pediatr 1975;87:184-9. 